\title{
004 OP THE USE OF USELESSNESS: COLLABORATIVE FAILURES AS POTENTIAL
}

D Funahashi. Department of Anthropology, Aarhus University, Denmark

\subsection{6/bmjopen-2017-016492.4}

Collaborations between individuals with different training and intellectual genealogies often build upon expectations of what the other can offer. This paper is based on one such collaborative experience with rehabilitative experts in Helsinki, Finland, who at first welcomed my participation as a trained ethnographer who could, they proposed, uncover and analyze for them how their patients "really felt" about their program for burnout. But later, what I provided for these clinical and rehabilitative experts was to prove a disappointment. "It's useless," they said of an article I had published based on my fieldwork at their center. What they had expected was a text that either verified or critiqued the effectiveness of the rehabilitative program that they had developed. Instead, the analysis I had produced as well as the ethnographic detail I had emphasized neither supported nor suggested what they could do to do better. Disappointment on my part came when the crisis of knowledge and of knowing I had hoped would emerge to spur discussion about the premises of the rehabilitative treatment failed to occur amongst my clinical collaborators. What, then, is collaborative work when the co-laboring fails to produce a vantage point from which each member finds "use"? And while being found useless is indeed the limit of collaboration, what potential can we find in ethnography that refuses to corroborate with the telos of clinical imperatives? What use can we find in uselessness? What kind of a "tool" is ethnography when found useless? 